\title{
Research of Politics under Information Technology and Social Linkage Mechanism
}

\author{
Yan Lijuan ${ }^{1, a}$ \\ ${ }^{1}$ Department of Stomatology, Xingtai Medical College,Xingtai,Hebei,054000,China \\ ayanlijuan2004@126.com
}

Keywords: network information technology, social participation, linkage, political construction

\begin{abstract}
According to the differences between network of public opinion and attitude of the government, the thesis marks off six basic types of citizen network participation in the public policy process, which are high efficiency type, low efficiency type, forced type, isolated type, suffocated type and common enemy type; according to the differences between the subjects initiated by network participation, it distinguishes three models of participation, which are bottom-up participation mechanism, the policy agenda of citizen network participation which is based on the investigation of empirical case as well as policy options and policy implementation. The thesis also repairs and expands the process models which are constructed in the introduction.
\end{abstract}

\section{Introduction}

Political participation refers to the behavior that citizens influence the political process through certain ways and channels. The of political participation theory in modern sense is derived from the thought of people's rights in the modern democracy theory [1,2]. The nature of democracy requires extensive political participation; therefore, political participation is not only the core of democratic politics, but also a necessary condition for the healthy functioning of the modern political system. If people can not meet the demands of political participation in reality, they will vent their feelings through the media, and use virtual space to obtain the demands of political participation [3]. For Chinese people, with the popularity of the Internet and the expansion of Internet users, the impact of the Internet on China's political life is becoming more and more significant. More and more people access to the political information and participate in political life by using the Internet. The failure of realistic way of citizen's political participation makes the citizens pin the hope of participating in government and political affairs on the Internet, and the update of the Party's ministerial principle provides legitimacy for network participation; the development of network economy and the change of economic situation at home and abroad enhance the ability and enthusiasm of citizen network participation; the rapid development of information technology and Internet technology create the possibility to realize network participation; the preliminary breeding and development of civil society in China ever become the booster of the growing network participation.

From the perspective of political communication, the thesis interprets network political participation, investigates network political participation in the interactive relationship between media and politics, and discusses the relationship between network and politics, which are regarded as the premise of analyzing network political participation in China. Combined with specific cases, the thesis conducts a systematic research on the problems like the theoretical basis and development background of network political participation, the influence of network political participation on Chinese political ecology, the specific forms of network political participation--- network monitoring, the realistic predicament of network political participation and so on. It also analyzes how to strength the way selection of network participation.

\section{Network political participation and public policy}

The Internet makes the transfer of political information more smooth as well as the interactive communication between transmitters and audience more convenient. The characteristics of the 
network media, such as decentralization, across time and space, interactivity and so on, promote citizens to focus and express views on public events. It is the promoting role it plays in the introduction of related public politics that makes us deeply know that the Internet offers public space for discussion as well as negotiation and good ways for political participation. Moreover, it provides citizens with an interactive discourse platform for a wide range of political participation, and the basis for the development of democracy in public policy as well.

As shown in Figure 1, the rise of the Internet has changed the dissemination pattern of traditional media news and information, and it also provides a more open space for public participation in public discussion and social management. To a certain extent, the Internet challenges the range and capacity of the information dissemination controlled by the political party, and becomes the channel to form, discuss and express public opinion without elites' control. In the political participation of citizens, the media, public and government form a structure of interactive relationship. Change of any part will affect the other two parties. In the perspective of agenda setting theory, the interactive relationship performs as the interaction and change among media agenda, public agenda and government agenda. Generally speaking, the traditional agenda setting is often from the top to the bottom, which means that government agenda affects media agenda; accordingly causing the public agenda change. The boundary among media agenda, public agenda and governmental agenda is less and less obvious, and there exists mutual influence and transformation among them. For example, the public express their views through the Internet and exchange their views, which form public agenda; public agenda raises wide public concern and media reports, which produce media agenda; some events will also cause the governments' focus and attention, as a result, which form government agenda.

The citizen political participation is the foundation of public policy. In modern society, the degree of the formulation on citizen participation in public policy has become one of the crucial indexes to measure the management level of modern government. In traditional society, citizens can participate in the formulation of public politics through the election, petition, hearing, participation in political parties as well as political groups and so on. With the development of information technology, the Internet offers citizens participation in public policy a platform for discussion, negotiation and interactive communication. The citizens' network participation in public policy is different from traditional media political participation. Network political participation influences political legitimacy. The public political legitimacy is an important concept in the process of public policy formulation. It refers to a behavior process that the legal public political subject provides political solutions with review and approval in accordance with the statutory authority and procedures, so as to make specific political solutions obtain legitimacy basis and status, and transforms it into formal politics, and obtains recognition and follow of society as well as the public.

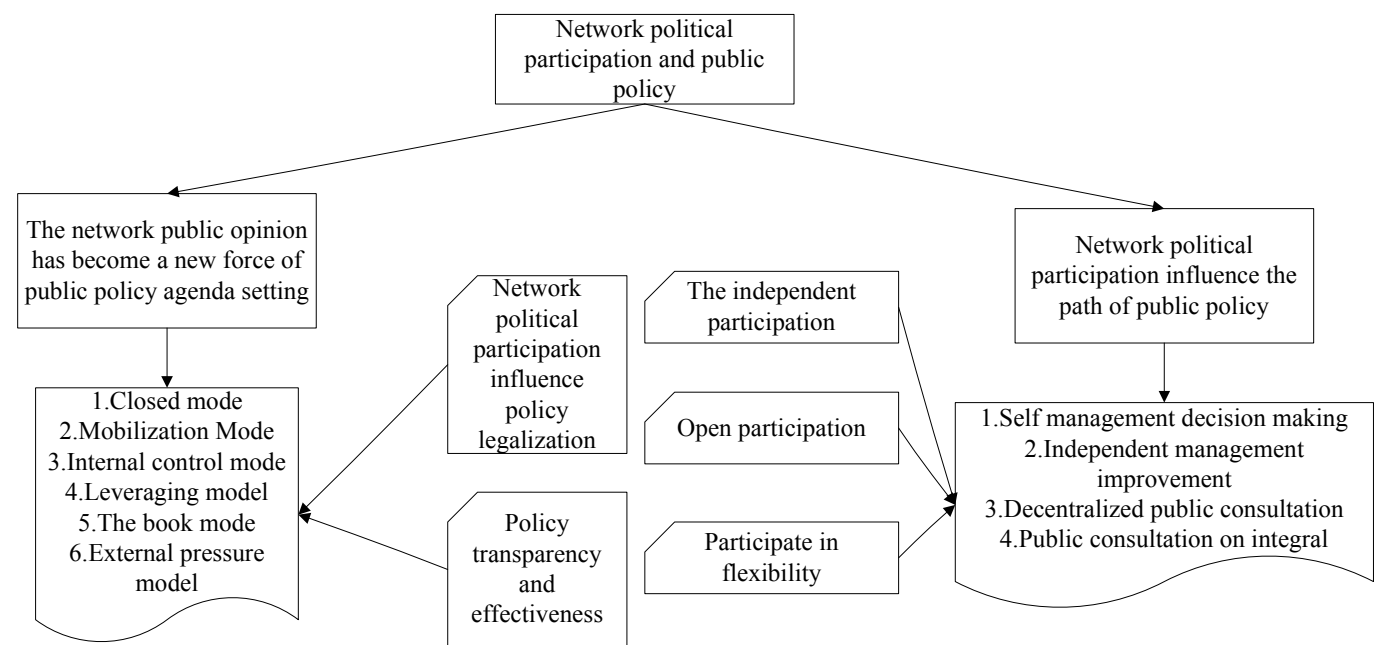

Fig.1. The process of network political participation and public policy

Network political participation influences the transparency and effectiveness of political formulation. Compared with traditional media, the Internet possesses technical characteristics of 
openness and diversity, which overcomes the disadvantages of traditional media's narrow information and low degree of openness. It realizes the mutual exchange of information and information communication all the times and places, whichauthorizes the public unprecedented words right during the process of network political participation. Everyone is a potential author of information. In order to realize the scientific and democratic public policy, the government should follow the scientific principle, adopt scientific analytical technique, and establish scientific and reasonable analytical model. Meanwhile, the government have to master comprehensive and accurate political information. Public network political participation can provide the government with the most original public opinion. At the same time, the transfer of public opinion in the network political participation is the most efficient. Due to the users' different social class, the opinions also reflects the interests demands of different groups and class, so as to provide more comprehensive information for governments' public political formulation.

\section{Approaches for citizen participation in political process under the information network}

With the popularity of the Internet, the development of BBS has entered a new field. BBS, which is based on the Internet, has appeared. As a result, the government agencies, business and computer companies have set up their own BBS, which makes it quickly became the forum of computer users to exchange information all over the world. The management structure of the network forum is like Pyramid. The supervisor locates at the top of BBS management, followed by the administrator, and nextare the moderators of all the layouts. All these people form the management system of the network forum. In the network forum, the levels of supervisor and administrator are abide by responsibility system, namely, the administrator must conduct daily work of the network forum well. According to rules and arrangements of the forum, they have to take charge of the community affairs, answer to the questions, approval and inspection of the moderators and editions within the jurisdiction. In addition, they also have responsibilities for community planning, column approval, the establishment of management permission, foreign communication, community announcements, coordination of community management team etc..

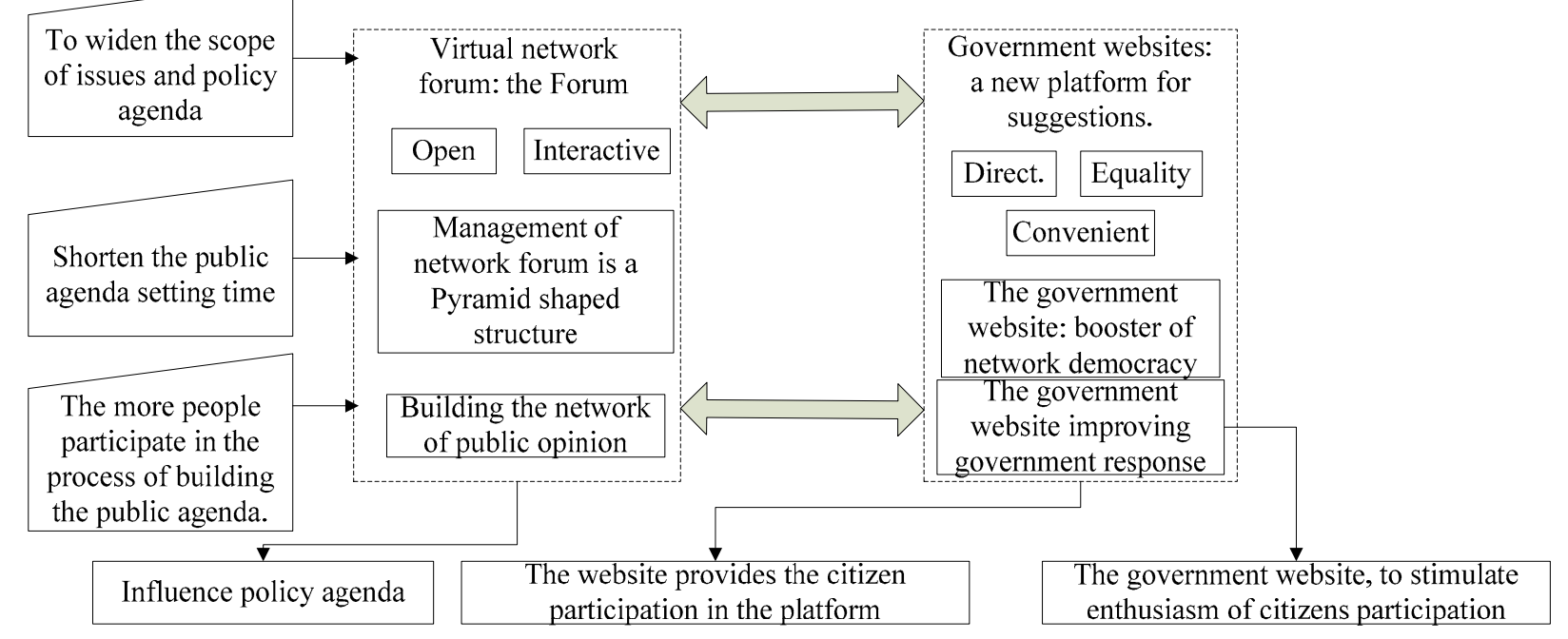

Fig.2.Approaches for citizen participation in political process under the information network

Fig. 2 shows the approaches for citizen participation in political process under the information network.

(1) The function of citizen participation in the network forum: shaping the network public opinion

Public opinion are integrated open public opinions that citizens can freely express comments and opinions on public affairs or social phenomenon through the Internet. It is a comprehensive reflection of citizens' views, opinions and suggestions on public affairs or social phenomenon in real life. The network public opinion uses the Internet and the Internet communication technology as the carrier, considers network citizens as the main expression, and regards public affairs or social 
phenomenon as the main concern object. Its essence is to succeed in mapping the real public opinion in the Internet space, and for most of the time, it performs the reviews and requirements on the governments' behavior or public policy.

(2) The implications of public policy in network public opinion: affecting the policy agenda

The policy agenda can be divided into two parts which are public agenda and governmental agenda. Public agenda refers to an agenda that some social problem has caused widespread concern of the public and social groups, and they put forward policy demands to government department, so as to take measures to solve them. In essence, public agenda is a way of citizen participation. In the age of the Internet, citizens express their opinions through network participation behavior like post and follow message, discussion and so on, which has changed the traditional way of policy agenda setting. It is mainly manifested in fig.3.

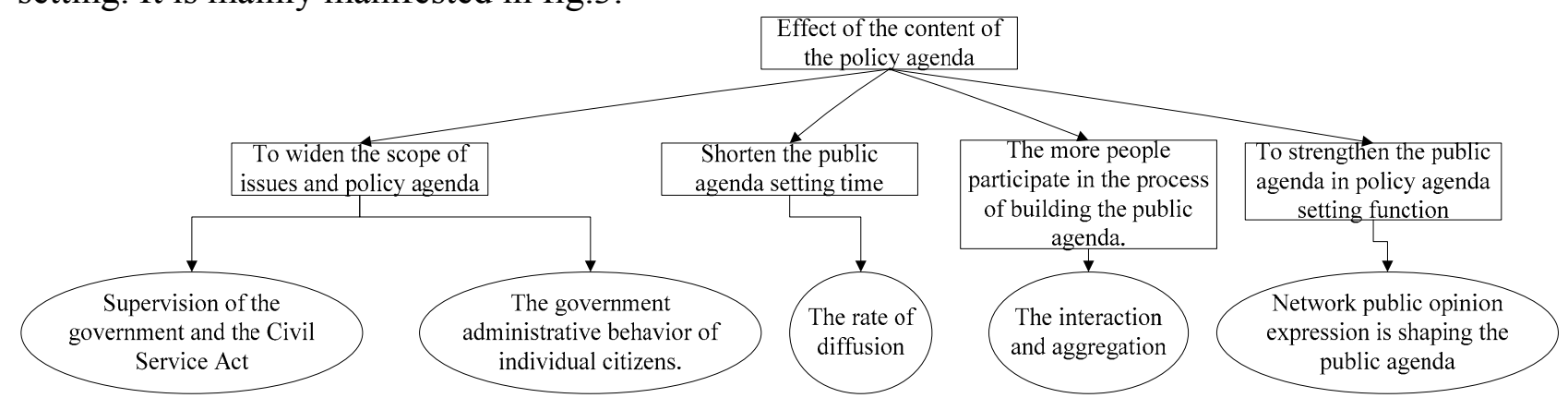

Fig.3. Content of influence on policy agenda

(1) Broaden the issues' scope of policy agenda. Network public opinion, as a source of policy agenda, has been highly praised by our government. During communicating with the network citizen, General Secretary Hu Jintao and Premier Wen Jiabao has always mentioned the significance of listening to network citizens' opinions to improve governmental work.

(2) Minimize the setting time of public agenda. Different from the expression of public opinion in reality, in the network society, since the social problems happen, then arise debate on the Internet, which lead to the escalation of network public opinion, at last form the network public opinion expression, it takes just a relatively short time. Once public issues raise public attention, its diffusion rate shows as geometric growth. The network public opinions can enter the government's line of sight in a very short time.

(3) More people participate in the setting process of public agenda. With the aid of the network forum platform, we achieve two-way interaction and multi-way communication. Public opinion expressions are easy to produce mass effect on the Internet, and enhance the possibility for the government to absorb public opinion.

(4) strengthen the role public agenda plays in the setting of policy agenda. In the network society with high information transparency, the stress of public opinion improves the public agenda's force, which makes the government consider public opinions to the greatest degree in the formulation of policies, so as to avoid to be blame for the breach of public opinion.

\section{The realistic predicament of China's political participation under the background of information}

\section{A. The impact and challenge of digital divide}

The internet affects every aspect of human society, and digital divide issue in the developmental process of the Internet also affects the development of network political participation in China. Digital divide issue is complex, and forms the developmental dilemma of current network political participation. Digital divide refers to the differences of information technology existing among countries, regions, industries, enterprises and individuals, as well as the gap of knowledge and information's absorption, understanding, application and creative ability on this basis. At present, digital divide issue in Chinese network political participation is mainly manifested in the different regions and groups. In particular, it can be divided into the following several aspects:

(1). Digital divide among different regions. In 2012, the scales of Internet users have different 
levels of growth in China's 31 inland provinces (cities, autonomous regions). Particularly, the Internet penetration rates in Beijing and Shanghai have reached the level of European countries and the United States. While, the Internet penetration rates in Shanxi, Hainan, Xinjiang and Qinghai provinces are between 40\%-50\%. And the Internet penetration rates in Inner Mongolia, Guizhou, Tibet and other provinces are less than $40 \%$. From this, we can conclude that there exists a big gap of the Internet penetration degree among different regions in China.

(2). Digital divide between urban and rural areas. There is still a great gap of the Internet penetration rate between urban and rural areas in China. The Internet penetration rate in urban area has reached $59.1 \%$, while that in rural areas is only $23.7 \%$.

(3). Digital divide among different industries and groups. Digital divide among different industries and groups are mainly manifested by that of different ages, different education backgrounds and different occupational groups.

With the information and network process continuously going deeper, the increasingly prominent issues raised by digital divide also brings great challenge and impact to network political participation in China. Specific performance is shown in Fig.4:

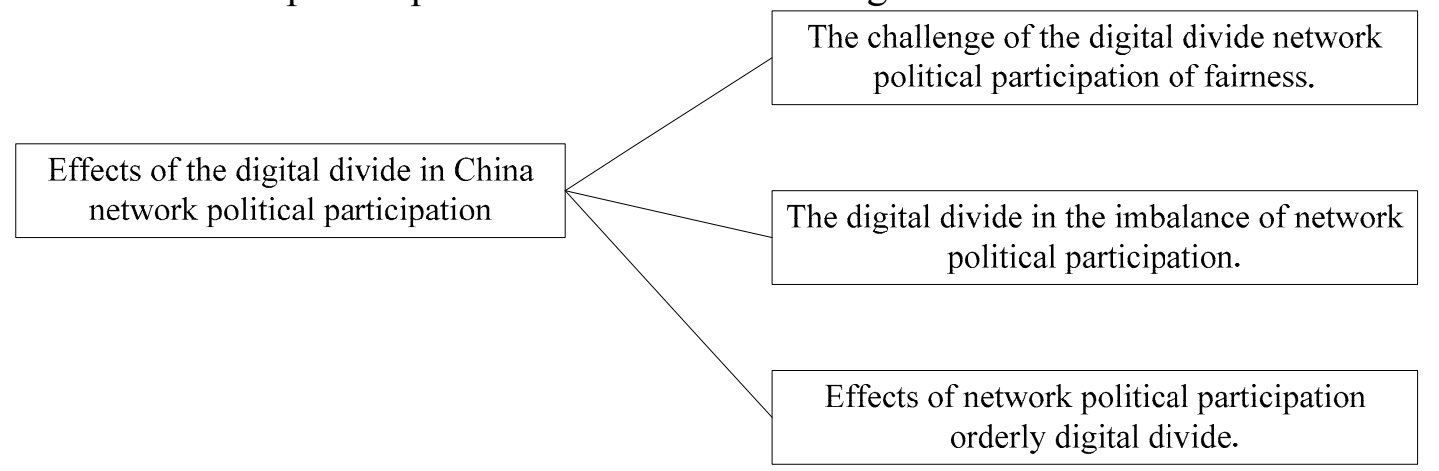

Fig.4. Effects of digital divide on network political participation in China

\section{B. The negative effects of group polarization}

Firstly, the effect of network anonymity. Since the Internet possesses the characteristics of convenience and diffusion, network users can achieve self expression through network platform, that is to say, the individual opinions about social issues and phenomena can be expressed through the channel of network. After a period of communication, individuals with opposite and favorable opinions gradually gather in groups in the process of evolution, and form group consensus. While, individuals holding neutral point of view appear in the edge of the group, and presents a tendency to decrease. Individuals with opposite and favorable opinions begin to be in the majority. Mapping to reality, it shows that individuals with neutral point gradually form opinion tendency through group discussions, and the group opinions have the tendency to the ends of polarization.

Secondly, the collaborative filtering function of network. Before the Internet, people rarely have the opportunity to choose information. They passively accept the information provided by the mass media in general. The Internet has provided enough information for people. While increasing the opportunity for people to access to information, it also provides tools and means of information selection, and enhances people's ability to choose information.

Thirdly, effect of silence. In network space, the motivation of social isolation has not disappeared; the way of pressure that network raises on personal views has changed, and the strength has become relatively weak, but its impact is still not optimistic; the motivation of herd mentality continues to exist, and the phenomenon of herd mentality is still widespread.

\section{Decision optimization of citizen participation in the political linkage}

\section{A. The logic of citizen network participation in public policy process}

The thesis argues that these actors who directly or indirectly influence public policy are the variables. Together these variables can form policy network of citizen network participation in public policy process. Meanwhile, they also determine the way, process and final participation effect of citizen network participation. Some of these variables exist in most cases of citizen 
network participation in public policy process, which play an important and decisive role in participation process and lead the whole process of citizen participation, such as network public opinion and government's attitude. In this thesis, these variable are called core variables. And there are some variables occasionally existing in some cases of citizen network participation in public policy process, and also play a certain role in participation process, such as political elites, intellectual elites, mass media, non-governmental organizations and so on. We call these variables peripheral variables.

Specifically, in some cases, a peripheral variable may become very important as a key factor for event. It may dominate the course of event and become core variable.

In this thesis, according to the strength of network public opinion and the government's attitude of support, acquiesce or opposition, we roughly divide citizen network participation in public policy process into six types, which are high efficiency type, low efficiency type, forced type, isolated type, suffocated type and common enemy type. As shown in table 1:

Table 1 the citizen network participation in the public policy process

\begin{tabular}{|c|c|c|}
\hline $\begin{array}{l}\text { Network public opinion } \\
\text { Government's } \\
\text { attitude }\end{array}$ & strong & weak \\
\hline support & $\begin{array}{l}\text { 1. high efficiency } \\
\text { type }\end{array}$ & 2. low efficiency type \\
\hline acquiesce & 3. forced type & 4. isolated type \\
\hline opposition & 5. suffocated type & $\begin{array}{l}\text { 6. common enemy } \\
\text { type }\end{array}$ \\
\hline
\end{tabular}

\section{B. The bottom-up participation mechanism}

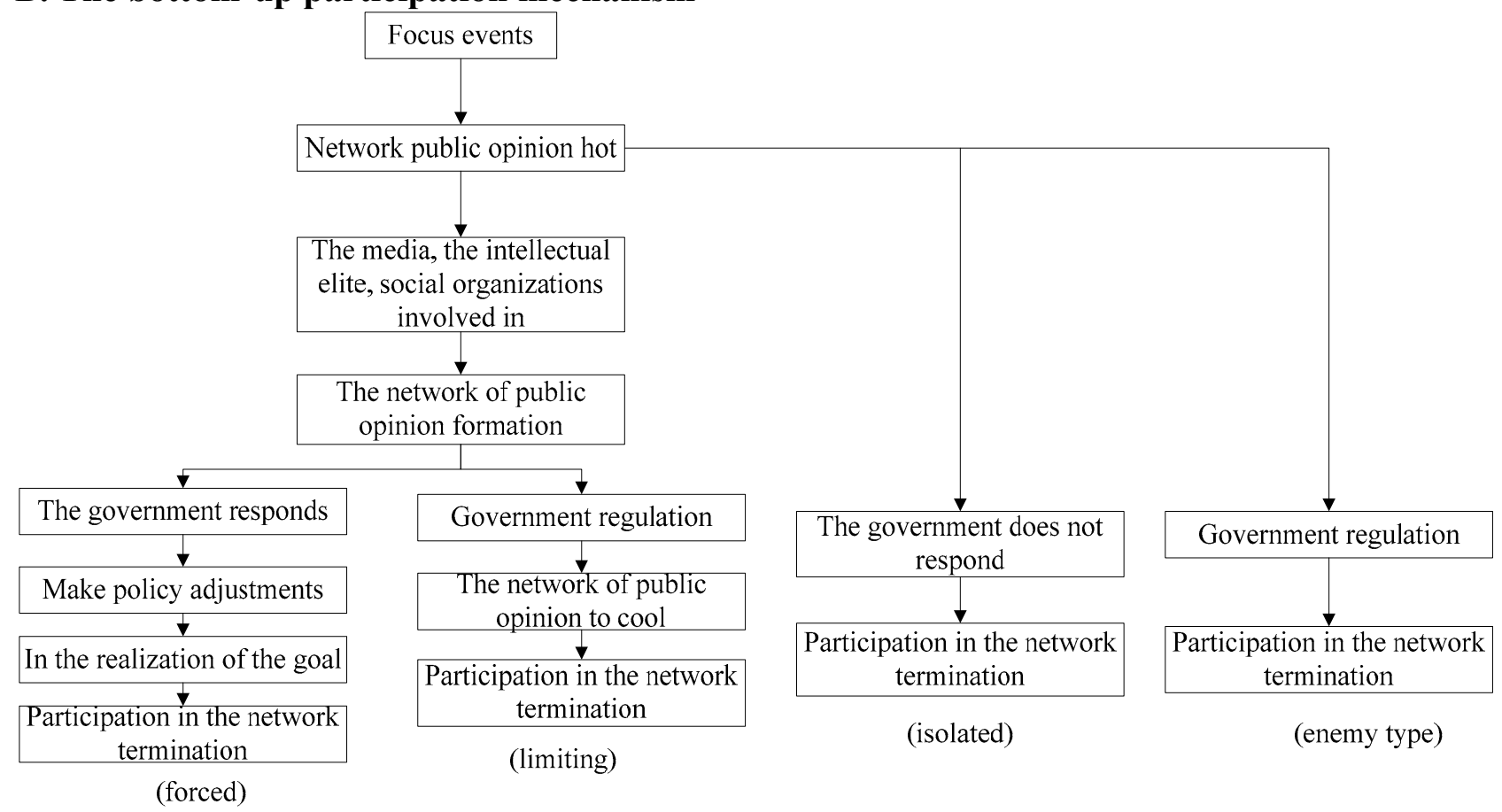

Fig.5. Model of bottom-up participation mechanism

In this thesis,according to the different combinations of the core variables, we divide citizen network participation in public policy process into six main types. In the perspective of dynamic participation process, there are two participation mechanism called bottom-up and top-down mechanisms. In the bottom-up participation mechanism, the participation subject is initiated by ordinary Internet users. Powerful network public opinions form on the Internet, and put stress on policy-making body along bottom-up way. It tries to influence public policy (see Fig.5 for model of participation mechanism). Under this kind of participation mechanism, the originating part of 
network participation is generally the appearance of event, and trigger a heated discussion on the Internet. Information is transmitted quickly on the Internet through lots of ways like network comments and reposts, so as to form network public opinion. At this point, influenced by core variables and peripheral variables in network participation, the bottom-up network participation will develop further along two different directions, and generate four different types of network participation.

\section{The model of citizen network participation in political process}

The thesis succeeds in abstractly summarizing the general model of citizen network participation in each stage of public policy process. It repairs and expands the process model constructed in the introduction. The agenda model of citizen network participation in public policy (see Fig.6) illustrates the process that citizen network participation successfully affects policy agenda. Generally speaking, citizen network participation in policy agenda is initiated by network users, and network public opinions are gradually transferred to the government, then the government makes adjustments on public policy in front of the powerful public opinion and sets up new policy agenda. Therefore, this model follows a bottom-up participation mechanism, and roughly belongs to forced type that is divided above. The main way of this type of network participation is network forums and micro-blog, which are easy to attract network users' attention in a short time, and rapidly form network applications of network public opinion.

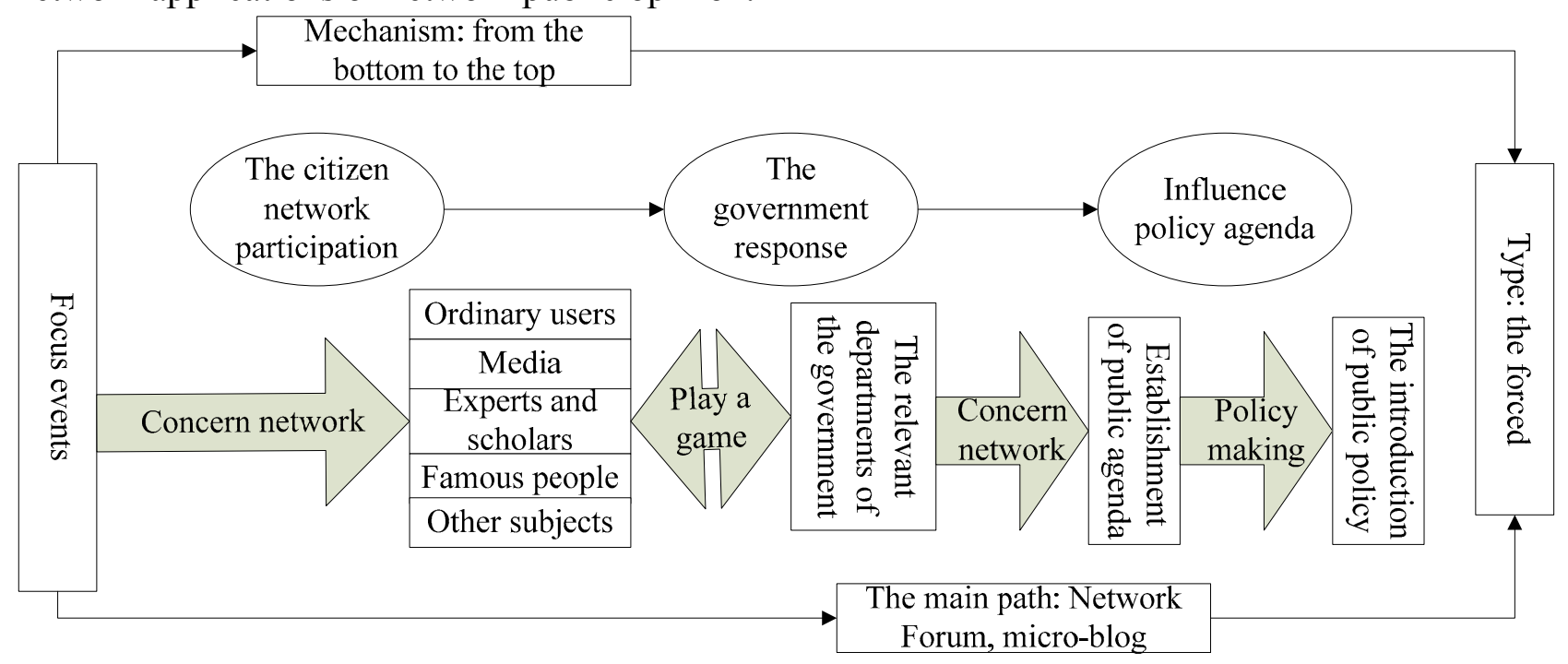

Fig.6. Model of citizen network participation in the public policy agenda

\section{Optimization of citizen network participation in public policy process}

\section{A. Construction of the security system of citizen network participation}

In order to narrow digital divide, citizen network should take part in basic security system. The government should adopt preferential policy and stimulus measure, meanwhile, strongly promote the Internet infrastructure construction in rural areas where the development of the Internet lags behind. The government should carry out effective supervision of network charge. Try to promote the Internet information technology education in the areas where the network is undeveloped and offer intellectual support to the information construction. The government should increase investment in the construction of public cyber source. In order to ensure low-income groups and vulnerable groups' rights of using the Internet, the grassroots organizations should set up public cyber source, regulate political program through micro-blog, and establish evaluation system of micro-blog performance on government affairs. The government officials should change the old concepts. The government should complete four "at the first time" for responding to network participation. The government should pay special attention to the timeliness in responding to network participation. Conducting a comprehensive response to network participation at the first time is a magic weapon to effectively guide citizen network participation. It's vital to improve the network media literacy of the government officials. 


\section{B. Promotion of the legislative process of citizen network participation}

For legislation, it is the first step to have clear legislative principle. Legislative principle is an important principle and basis for legislative bodies to main laws, which embodies the internal spirit of legislation. The law-making must be carried out under the guidance of legislative principle, and effectively regulate the behavior of citizen network participation and protect their rights, so as to complete a better realization of legal function. The legislation of network participation suggests: protect citizens' freedom of speech on the Internet and accurately define the scope of protection for freedom of speech on the Internet.

\section{Shaping of ethics and morality of citizen network participation}

To establish and perfect the law as well as system of citizen network participation is an effective tool to promote network participation. Due to the Internet's characteristics of openness and anonymity, ensuring the health and orderly development of network participation basically needs moral self-discipline. In order to cultivate the spirit of the citizen network participation, the government should actively create and extensively promote ways as well as approaches of network participation. Try to offer convenience to citizen network participation and guide citizens to establish the subject consciousness of political participation. Besides, the government also manage to mobilize citizens' enthusiasm and create social atmosphere of network political participation, discussion and inquiry in the whole society. To construct administrative ethics in network era, the government should set up the consciousness of citizen consultation. In addition, the government must follow the development of the times, completely change the traditional stereotype of official standard thought, and establish the spirit of consultation for discussing with citizens on public affairs. Only if the governments put a low position and make equal dialogue and consultation with citizens through open decision-making model, can they truly absorb the views of citizens and have a real effect on the behavior of citizen network participation.

\section{Summary}

The citizen network participation in political process will become a flash point of democratic politics and democratic construction of decision-making system with Chinese characteristics. By absorbing the network public opinion, the foundation of public opinion of Chinese public policy will be more broad, and much closer to the target of democratic and scientific decision-making. With the continuous expansion of the depth and breadth of network participation, Chinese people's sense of participation, subject consciousness, and right consciousness will continue to increase. People can play a more important role in Chinese public policy process. Through a specific research of the background, approach, stage and government's response of citizen network participation in public policy process, the thesis draws the conclusion: network public opinion and government's attitude are core variables to affect citizen network participation. Political elites, intellectual elites, mass media, social organizations, celebrities are peripheral variables. In order to build the security system of citizen network participation, we should narrow network digital divide, increase the level of government websites and micro-blog of government affairs and strengthen the response to network participation; what's more, we should also promote legislative process of citizen network participation, protect citizens' freedom of speech on the Internet; shape ethics and morality of citizen network participation, advocate moral self-discipline of citizen network participation, cultivate the spirit of citizen network participation and construct administrative ethics in the era of network.

\section{References}

[1] Chen Zhenming. The Policy Sciences---Introduction of Public Policy Analysis. Beijing: China Renmin University Press (2003), p223.

[2] Du Junfei. The Government Network Crisis. Beijing: China Development Press, 2011, p117.

[3] Li Bin. An Introduction to Political Science. Beijing: China Social Sciences Press, 2006, p115. 
[4] Pramod K.Nayar, Virtual Worlds.Culture and Politics in the Age of Cybertechnology, London:Sage Publications Ltd (2004).

[5] Andrew Chadwick.Internet Politics:State, Citizens and New Communication Technologies, Preface.Oxford University Press, (2006).

[6] Wang Shuliang. An Outline of Network Political Culture. Theory and Reform, vol.5, 2012, p17-19.

[7] Ding Zhigang, Dong Hongle. Analysis of Political Identity Level. Study and Exploration, Vol. 52010, p223-225.

[8] Xiong Guangqing. China Network Politics and Political Culture Changes. Social Science, Vol. 12012 , p336. 